\title{
Discussions on Architectural Engineering Bidding Skills Zhiguo Huang
}

\author{
Chongqing Vocational Institute of Engineering, Chongqing, 402260, China
}

\author{
Keywords: Architectural engineering, Bidding, Offer, Skills
}

\begin{abstract}
Architectural engineering bidding is a piece of specialized work in which various factors such as subject, object and environment should be considered. Therefore, it is required to use skills of engineering budget making, engineering bidding decision and engineering bidding offer in the process of architectural engineering bidding. Moreover, great importance should be attached in ideological understanding. Efforts shall be made to realize organization guarantee and ensure an ideal performance in bidding.
\end{abstract}

\section{Introduction}

In architectural engineering bidding, the bidder organizes workers to discuss reasonable bidding strategies carefully according to requirements of tendering document and individual ability and management level and strives to obtain the qualification for winning the bidding through specified procedures such as bid opening, bidding evaluation and award of bid. In this process, it is required to make various preparations before bidding, understand specific requirements of tendering accurately, master details of the tendering document specifically and organize relevant personnel to study strategies and skills for architectural engineering bidding carefully so as to guarantee the smooth implementation of engineering bidding process, improve bid acceptance probability and achieve the ultimate goal of bidding. With the sustainable development of economy, construction industry has developed rapidly. However, with the development of socialist market economy with Chinese characteristics, architectural engineering enterprises must attach great importance to architectural engineering bidding affairs and conduct in-depth research on how to implement engineering bidding work under the new situation.

\section{Engineering budget making skills}

Engineering budget is an important fundamental basis of engineering construction investment, appropriation and final settlement of party A and party B as well as an important indicator for tendering and bidding offer and pricing of engineering projects. Currently, construction enterprises in Chinese construction market generally obtain a project through bidding. Therefore, budget making work seems very important for building construction enterprises. Only with careful preparation and scientific budge making can building construction enterprises effectively improve their offer ability and stand out from the crowd in the increasingly fierce market competition. In the process of budget making for architectural engineering projects, it is required to be familiar with connotations of quota, procedure and specific items, go deep into engineering site, collect relevant data from feasibility study, preliminary design and construction drawing design and make preparations for budget making. Various data prepared should cover geological report of engineering investigation, topographic map and construction design drawing. It is required to investigate the construction environment carefully through field visit, implement building construction organization design work, collect current architectural engineering budget quota and fee collection standard, understand budgetary price of materials in the local region and implement methods of budge making; be familiar with construction drawings of engineering project and calculate work amount carefully; apply computation rules of architectural engineering quantity expertly, read relevant drawings carefully, conduct in-depth research on general arrangement plan, master the general view of this project and know the project fairly well. When studying professional drawings, it is also required to understand the intention of the designer and contents expressed by drawings at any time. Design modifications made before 
construction should be known actually. Only in this way can it be possible to implement budge making reasonably, calculate the required engineering quantity carefully, use the unit price reasonably and prevent problems such as calculation omission, repeat or error. Currently, with the application of computer, it plays a vital role in engineering budget making. Both the amount of budget work and the occurrence probability of human error are reduced. In the calculation, it is necessary to constantly improve the precision of original data input. This requires us to have in-depth understanding of the attraction of architectural engineering projects for construction personnel based on the reality and strive to carry out budget making work fairly and reasonably.

\section{Engineering bidding decision skills}

A building construction enterprise might meet the opportunity of simultaneous tendering and bidding of multiple engineering projects. Due to the limitation of construction ability, it cannot obtain the opportunity of bidding for multiple projects at the same time. It should choose among multiple engineering projects. For a project, enterprises should consider bids of profit making, breakeven and loss from the perspective of benefit. Building enterprises should implement bidding decisions according to features of each project and their actual situation so as to achieve work objectives. Specifically speaking, the following situations should be considered comprehensively: first, the possibility of winning the bidding and the feasibility of bid project, i.e. whether the enterprise has the ability to implement this project well and transfer the corresponding management team and technical talents to participate in the specific implementation of this project, and whether the competitor has significant advantages. Second, the reliability of bid project, e.g. whether urban planning permit and land certificate approval of engineering project are completed and whether project fund can be put in place on schedule. Third, specific conditions of contract of bid project. Forth, various internal and external factors influencing bid winning. The former mainly includes the comprehensive strength of an enterprise in technology, management and reputation. The latter mainly includes the status of owner and supervision engineering personnel, status of competitor, environment of laws and regulations and project risk degree. In the following cases, the bidding can be abandoned: I. The scale and technical requirements of the engineering project exceed the technical ability of the company; II. The engineering project exceeds the business scope and business capacity of the company; III. The company has saturated contracting missions currently and will be unable to undertake the project if winning the bidding; IV. Technical ability, operation capacity and construction ability of this company are inferior to the competitor.

\section{Engineering bidding offer skills}

Engineering bidding offer skills refer to reasonable offer methods used according to the practical situation in project bidding. It is required to carefully study and master specific offer skills for both domestic bidding and international bidding. This has vital significance for winning the right to bid. Several common engineering bidding offer methods are listed as below:

First, multi-scheme offer skill. For any tendering document, once it is found that the scope of engineering project is not very clear and some articles in the contract are not clear or fair enough or technical requirements are too rigorous, the bidding enterprise can organize experienced technical experts to study the design and construction scheme of tenderer carefully before offer and handle the problem with the method of multi-scheme offer under the premise of comprehensive risk prediction. This requires offer according to requirements of the tenderer; otherwise, the bid might be rejected. Then, the reduced price after the occurrence of change of an article can be put forward. In this way, the owner can be attracted more and the probability of winning the bidding can be improved.

Second, offer skill of adding suggestions. If the owner allows the bidder to make suggestions otherwise in the tendering document, the bidder can use the method of modifying the original offer and put forward a new scheme. At this time, the bidding enterprise should seize the favorable opportunity, organize experienced designers to conduct in-depth research on the original document of the tenderer and control costs with optimal technological process and improved technologies so as to 
increase the probability of winning the bidding. However, importance should be attached to the following when suggestions are made: on the one hand, due to the short time of bidding, uncertain suggestions (if any) might cause a lot of unnecessary problems. Therefore, suggestions must be feasible and would better be practical experience. On the other hand, contents of the scheme should not be listed in great details. Key links in the scheme shall be reserved to avoid leakage of secret.

Three, offer skill of approaching to price ceiling. For a project with great advantages in the decision process and confidence of success, the bidder can use the method of approaching to price ceiling. For unideal engineering projects, the bidder shall bid with a price slightly lower than the price ceiling and implement the project once wining the bidding. It is not a pity even if the bid is not won. This skill applies to the following four situations: first, for projects that an enterprise is not very interested in, it can bid with the principle of no price reduction; second, projects in which an enterprise has absolute advantages and can win the bid with its strong actual strength; third, projects with advanced fund paying and high risk degree; finally, pure professional projects. Such projects have very high requirements for professional technologies and an enterprise is good in this aspect and has corresponding qualification, rich experience and good reputation beyond the reach of other enterprises.

Forth, offer skill of reserve bid price. The whole process of engineering bidding is the process of fierce competition among various construction enterprises in essence. Competitors often pay attention to the offer of other parties. Therefore, it is very difficult to actually guarantee the absolute confidentiality of offer. This requires persons participating in bidding offer to play to the score and use reserve bid price for bidding once finding the first competitor absent. In this way, a good result can often be achieved.

Fifth, skill of union type offer. This skill is very common in reality. Two or three companies have similar main business. If one single company bids separately, problems might occur, such as inadequate experience or performance, excessive work load and high offer, which will cause the loss of competitiveness. The method of joint bidding can allow companies to complement advantages of each other and avoid disadvantages so as to achieve interest and risk sharing and improve market competitiveness and the probability of winning the bidding. This method is used in a lot of domestic engineering projects.

Sixth, offer skill of surprise attack. Considering the fierce competition for bidding in the current building market, to effectively confuse competitors, an enterprise can pretend to offer according to general situations and even disclose some false information intentionally or unintentionally, e.g. claim that it is not very interested in the project and does not plan to bid with a high price or even do not want to bid, which can relax opponents. Then, it can suddenly join in the bidding when the bidding is about to end and lower the offer intentionally so as to win the project.

Seventh, offer skill of unbalanced unit price. This skill is a common method in international bidding offer. Unbalanced unit price mainly means that the unit price of some items is higher than the normal level and that of some other items is lower than the normal level on the basis of not influencing the overall bid price level. Therefore, it is required to avoid excessively high or low price, thus avoiding reducing the opportunity of winning the bidding or causing bid rejection. The author thinks that skillful use of this offer skill is helpful to shorten the time of fund withdrawal and transfer corresponding risks. On the one hand, the time of fund withdrawal can be shortened. Once it is necessary to pay according to the progress of works, there will be great financial pressure in the earlier stage. In view of this, during engineering project bidding offer, unbalanced offer skill can be used to increase the profit of some early works, such as earthwork, foundation and structural engineering. The reasonable increase of profits of such engineering and decrease of profits of later works such as paint and exterior wall decoration do not have substantial influence on the cost of construction of the whole engineering project. In this way, if winning the engineering project, the enterprise can avoid the problem of financial strain in the earlier stage due to the lack of material preparation funds to a great extent, strengthen project fund withdrawal and improve its benefit indirectly. On the other hand, the profit space of the project can be expanded through risk transfer. For engineering projects with total price contracting, unbalanced offer method can be used to increase the 
profit of modified engineering and control risks effectively. For example, for projects with the possibility of continuous enhancement expected in the list of work amount, the unit price can be increased reasonably; for those with the possibility of continuous decrease, the price can be reduced reasonably. However, careful analysis should be conducted when this method is used so as to avoid disgust of the owner.

Eighth, bidding skill of low-profit offer. When architectural enterprises are faced with severe survival and development crisis and lose a lot of market shares and policies issued by the state are adverse to their survival, they cannot increase profit blindly; instead, they should strive to win the bidding under the situation of breakeven so as to tide over difficulties and survive. This skill is mainly used in the following situations: a company has unsaturated project tasks, idle personnel and survival crisis; it fails in bidding for many times; national policies change and investment is adjusted. For example, once railway capital construction is cut down, a lot of railway enterprises cannot win a project and thus fall into danger. When bidding in the newly explored market, enterprises should give up profit and first strive to go into the new market, form a good reputation and lay a good foundation for occupying the market in the future. Enterprises need to create good performance urgently. When an architectural construction enterprise needs to achieve a good performance urgently, it can consider to win the bidding at the sacrifice of certain profits.

\section{Conclusion}

In conclusion, architectural engineering bidding is vital work. The success or failure in winning the bidding will influence the future development of an enterprise. Therefore, it is required to attach great importance and strive to achieve the ideal result. Careful organization is a key link in the implementation of engineering project. A bidding team with high quality is the key factor of success. It is required to conduct scientific analysis, establish project bidding team and endeavor to conduct analysis, planning and decision making of engineering projects in each bidding process. Once the bidding is won, the smooth implementation of the project shall be guaranteed. Therefore, relevant laws and regulations should be followed in architectural engineering project bidding. All feasible bidding skills should be adopted to guarantee the ability to achieve the expected goal in bidding.

\section{References}

[1] Jiang Jiaxiang. Discussions on Architectural Engineering Bidding Offer Skills. China Construction, 2012(6).

[2] Wu Weibang. Architectural Engineering Bidding Offer Strategies and Pricing Skills. Guangdong Building Materials, 2012(8).

[3] Shi Jian. First Exploration on Architectural Engineering Bidding Offer Strategies and Pricing Skills. Architecture, 2012(22).

[4] Xue Fei. Brief Discussions on Architectural Engineering Bidding Skills. Tendering and Bidding, 2014(11).

[5] Yang Rong. Discussions on Bidding Strategies and Offer Skills for Architectural Engineering Projects. Scientific and Technological Innovation and Application, 2014(22). 